\title{
Digital Guidance for Susceptible Readers: Effects on Fifth Graders' Reading Motivation and Incidental Vocabulary Learning
}

Journal of Educational Computing

Research 2018, Vol. 56(I) 48-73

(C) The Author(s) 2017

Reprints and permissions: sagepub.com/journalsPermissions.nav DOI: I0.I I77/0735633 I I7708283 journals.sagepub.com/home/jec @SAGE

\section{Thijs M. J. Nielen', Glenn G. Smith², Maria T. Sikkema-de Jong ${ }^{1,3}$, Jack Drobisz ${ }^{2}$, Bill van Horne ${ }^{2}$, and Adriana G. Bus ${ }^{4}$}

\begin{abstract}
In this digital era, a fundamental challenge is to design digital reading materials in such a way that they improve children's reading skills. Since reading books is challenging for many fifth graders-particularly for those genetically susceptible to attention problems - the researchers hypothesized that guidance from a digital Pedagogical Agent (PA) could improve students' reading motivation and incidental vocabulary learning. Using a sample of 147 fifth-grade students, the researchers carried out a randomized control trial with three groups of students reading: (a) hardcopy (print) books, (b) digital books, and (c) digital books with a PA. For students with a genetic predisposition to attention problems, carriers of the DRD4 seven-repeat allele, the PA supported their incidental vocabulary learning. For noncarriers, there were no effects of the digital reading materials or the PA.
\end{abstract}

\footnotetext{
'Centre for Learning Problems and Impairments, Leiden University, Leiden, The Netherlands

${ }^{2}$ University of South Florida, Tampa, FL, USA

${ }^{3}$ Leiden Institute for Brain and Cognition (LIBC), Leiden, The Netherlands

${ }^{4}$ Vrije Universiteit Amsterdam, Amsterdam, The Netherlands
}

Corresponding Author:

Adriana G. Bus, Vrije Universiteit Amsterdam, De Boelelaan I 105, I08I HV Amsterdam, The Netherlands.

Email: a.g.bus@vu.nl 


\section{Keywords}

in-school free reading, digital reading, susceptibility genotypes, attention problems, differential susceptibility, digital pedagogical agent, randomized control trial, guided reading, vocabulary learning, reading motivation

\section{Introduction}

Although recreational reading is vital for reading skill development, a substantial proportion of students stop reading recreationally late in primary school (Nielen \& Bus, 2013). When students lose interest in reading at this early age, their reading skill development levels off (Chall, 1983). As a result, their reading development in the long run is at risk. Independent reading is essential, not only for an autonomous orthographic lexicon (Share, 2008) but also for new vocabulary and reading comprehension skills (Mol \& Bus, 2011). Without engaging books and sufficient practice, reading skills remain underdeveloped and students may end up in a downward causal spiral of disinterest and decreasing time spent reading (Nielen \& Bus, 2015). A substantial proportion-about half of Dutch adolescents - reported that they almost never read for enjoyment (OECD, 2010). It is easy to predict serious consequences of what has been termed aliteracy (Boorstin, 1984) - poor reading due to lack of practice - not only for individual students' academic and professional success (Gottfried, Schlackman, Gottfried, \& Boutin-Martinez, 2015; Mol \& Bus, 2011; Notten, 2011; OECD, 2010; Taylor, 2013) but also for society as a whole. There is a serious risk that many individuals will not develop the literacy skills needed to function as full members of contemporary society and may not benefit from the 21 st-century informationage economy (EU High Level Group of Experts on Literacy, 2012).

Kirschner, Sweller, and Clark's (2006) argument that unguided or minimally guided instructional approaches are less effective than guided instruction may also apply to the domain of reading. For many students, reading comes too early as an activity that they feel compelled to practice without support. Especially when students fail to understand age-appropriate reading materials when unguided, reading may be frustrating and this may eventually result in withdrawal from reading. For optimal reading practice, after the initial stage of intensive reading instruction in elementary school, we need to find ways to guide students while reading text. In the current study, the researchers explored the potential of a digital Pedagogical Agent (PA) in digitized books, appearing at the end of each chapter, to provide encouragement and to foster sustained effort during reading. Pedagogical Agents are defined as virtual characters embodied with human-like qualities of speech, gesture, or movement (Johnson, Rickel, \& Lester, 2000; Sweller, Ayres, \& Kalyuga, 2011) that are known to improve learning in multimedia environments (Schroeder, 
Adescope, \& Gilbert, 2013). The researchers modeled the PAs in the books on aspects of adult scaffolding that have proved to sustain reading of fiction (Teale et al., 2013).

\section{Guidance During Reading}

Effective adult tutors typically show interest in the book that the child is reading. See experimental evidence from so-called SMART (Start Making A Reader Today; Baker, Gersten, \& Keating, 2000) and similar studies (e.g., Rimm-Kaufman, Kagan, \& Byers, 1998). Students in these experiments were individually tutored for 1 or 2 hours a week by trained volunteers who initiated discussion about the book's focal theme; what happened in the book and why; and any relationship of events, characters, and situations in the book to the reader's personal life. In the same vein, there are correlational findings indicating that students stay more motivated to read when they have a chance to discuss books with their parents (Nielen \& Bus, 2013).

The main aim of the current study was to test whether fiction books with a Pedagogical Agent (PA) embedded in the digital book can foster sustained independent reading in fifth graders, resulting in more learning from reading, particularly in incidental vocabulary learning. Incidental vocabulary learning is defined as vocabulary growth, due to encounters with words during independent reading, without explicit teaching (Cunningham, 2005; Swanborn \& de Glopper, 1999). The researchers focused on fifth graders because these students are able to read independently but still require a lot of practice to strengthen their reading skills.

PAs added to digital fiction books may encourage students to continue reading. Since there is some evidence for the efficacy of anthropomorphic characters with spoken, as opposed to written, feedback (e.g., Heidig \& Clarebout, 2011; Lusk \& Atkinson, 2007), the PA in the current study was designed as an animated, speaking mouse with anthropomorphic features in appearance and speech. Unlike digital reading tutors in other programs, the PA in the current study did not teach specific strategies such as self-questioning or identification of main ideas, followed by elaborate feedback, as students tried to apply the learned strategy (e.g., Meyer et al., 2010; Mich, Pianta, \& Mana, 2013; Sung, Chang, \& Huang, 2008). Unlike other reading support systems such as Meyer et al. (2010), who provided explicit instruction on how to identify and use text structures, or Sung et al. (2008) who instructed students about concept mapping and highlighting important messages, the current study did not provide explicit instruction on reading strategies.

Instead our PA provided emotional support by showing interest in how the story relates to students' personal experiences similar to other interventions (e.g., Baker et al., 2000; Rimm-Kaufmann et al., 1998). The PA in the current study complemented the student upon having read each chapter. He summarized main 
events in the story ("We know now that Faiza is angry with her best friend") and stimulated students to relate the content of the story to personal events in their own lives ("Have you ever had a fight with your best friend?"). Our PA provided a combination of information and encouragement, which may be most effective in enhancing both learning and motivation (Baylor \& Kim, 2005; Kim \& Baylor, 2016). Furthermore, the PA offered content-related interaction, which may be more supportive than just providing incentives without interaction.

\section{Media Comparisons, Digital Versus Print Reading}

Although several studies have compared digital reading with print reading in terms of reading motivation and reading comprehension, the results are somewhat contradictory. Due to numerous possible distractions (checking emails or social media for instance; Daniel \& Woody, 2013) and difficulties with navigation (e.g., scrolling and the lack of an overview of the entire text; Mangen, Walgermo, \& Brønnick, 2013), digital reading materials may sometimes result in failure to understand the structure of the text. This may negatively impact reading speed, reading comprehension, and reading motivation. However, Taylor (2011) found no differences between digital and print reading on reading comprehension, indicating that reading of digital text may be at least as good as reading print. Some studies suggest that reading of digital texts may also present certain advantages. Reluctant readers may actually prefer to read digital books, because digital reading provides the opportunity to read easy books without their peers noticing (Miranda, Williams-Rossi, Johnson, \& McKenzie, 2011). Digital reading may even attract reluctant readers who have had negative experiences with traditional reading materials (Tveit \& Mangen, 2014).

To address the influence of the medium on reading, the researchers compared reading of print books with reading of digital books. As opposed to most prior studies (for an exception, see Miranda et al., 2011), students in the current experiment could choose from a larger collection of books. They read complete storybooks, which is more authentic and more comparable to students' normal reading activities than the reading of fragments used in most prior studies.

\section{Differential Susceptibility to Pedagogical Guidance}

Most students perform reasonably well in spite of large variation in the quality of instruction across schools (e.g., Pressley, 2006). Building on the evolutionaryinspired proposition that some students may be more strongly affected-both for better and for worse-by the instruction, it is expected that some children's performance strongly depends on its quality (Belsky, Bakermans-Kranenburg, \& van IJzendoorn, 2007). In particular, genetic markers appear to be strong indicators for children's susceptibility to educational input (for an overview, see Bakermans-Kranenburg \& van IJzendoorn, 2011; van IJzendoorn \& 
Bakermans-Kranenburg, 2015). Carriers of the long variant of dopamine-related genes, the DRD4 seven-repeat allele targeted in this study as well, are particularly responsive not just to qualities of the social-emotional environment but also to the way their learning is guided (see Kegel, Bus, \& van IJzendoorn, 2011; Plak, Kegel, \& Bus, 2015 for evidence in younger children). Genetic susceptibility means that carriers of a particular gene, the DRD4 seven-repeat allele, are more susceptible to environmental influences, whether positive or negative (Bakermans-Kranenburg \& van IJzendoorn, 2011).

It is possible that the prefrontal lobe (the part of the human brain that inhibits inappropriate impulses and emotions from the limbic system) is less efficient in carriers of the long variant of the DRD4 gene (susceptible children). Research to date did not reveal empirical evidence for attention problems of carriers of the DRD4 seven-repeat allele (Pappa, Mileva-Seitz, Bakermans-Kranenburg, Tiemeier, \& van IJzendoorn, 2015). However, there is experimental research suggesting that intensive, closely monitored, and individualized guidance offered by technology-enhanced reading materials may, more than traditional reading materials, enhance the learning potential of susceptible children. In experiments with 4-year-old emergent readers, studies revealed evidence for the hypothesis that susceptible children benefited more from technology-enhanced materials than their peers. Carriers of the long variant of the DRD4 genotype benefited more from intensive, closely monitored, and individualized guidance of a computer program, as compared with their genetically less susceptible peers (Kegel et al., 2011; Plak et al., 2015). In other words, there is evidence showing that technology can turn a putative risk group into a successful group when the program is enhanced with individualized guidance. In the same vein, the current study tested whether a PA providing the perception of intensive, closely monitored, and individualized guidance while reading fiction books supports learning in a genetically susceptible group.

\section{Current Study}

This study was focused on fifth-grade students reading storybooks during 8 hours spread over 2 months in three experimental conditions comprising reading: (a) regular print storybooks, (b) digital storybooks, and (c) digital storybooks with a PA providing guidance during reading. The researchers chose incidental vocabulary learning as an outcome measure to test the effects of reading on learning, assuming that new vocabulary is one of the significant learning effects of reading (Swanborn \& de Glopper, 1999) and may be a sensitive measure for the effects of book reading (Mol \& Bus, 2011). The researchers also assessed children's reading motivation as an indicator for intervention effects. In addition, the researchers accounted for a marker of genetic susceptibility to test the hypothesis of genetic susceptibility. 
The following questions were addressed:

1. Does the medium (print vs. digital) through which books are presented influence reading motivation and incidental vocabulary learning?

Digital reading, in contrast to hardcopy books, may improve reluctant readers' reading motivation (e.g., Tveit \& Mangen, 2014) but may also hamper learning of new vocabulary (e.g., Daniel \& Woody, 2013).

2. Can a PA providing information and encouragement during reading help students become more motivated to read and learn more new vocabulary from reading?

3. Is the PA particularly effective for reading motivation and vocabulary learning of students who are more susceptible to the quality of guidance while learning?

The researchers hypothesized that a PA can support susceptible students' reading and that low-susceptible individuals would be less affected by a PA (cf. Kegel et al., 2011; Plak et al., 2015).

\section{Method}

\section{Design}

A schematic overview of the design and time course of the study is presented in Table 1. For reading ability, the researchers obtained the results of a standardized reading comprehension test administered by teachers in all participating schools prior to the study. Researchers pretested and posttested reading motivation and vocabulary learning. During the 8-week intervention, students independently read about 1 hour per week in the classroom or another location in the school in one of the three study conditions: (a) reading self-selected hardcopy (print) books, (b) reading self-selected digital books, and (c) reading self-selected digital books with guidance from a PA. The duration of the intervention provided students with the opportunity to read at least one, but likely multiple, books. At the same time, the duration of the intervention was limited to enable that it could be carried out within the regular curriculum.

To account for limited availability of computers in the classroom, no more than six students per classroom participated. Because many parents refused to let their children participate in the study due to the genotyping, there were less than six students available in some classrooms. The researchers explained that data would be destroyed after genotyping and data files would not include names; however, many parents were still concerned about a DNA analysis. In classrooms with less than six students with parental consent, three students 
Table I. Schematic Overview of the Design and Time Course of the Experiment.

\begin{tabular}{|c|c|c|}
\hline Study phase & Time & Activities/tests (administered by) \\
\hline Pretest & Week I & $\begin{array}{l}\text { - Reading ability (teacher) } \\
\text { - Saliva collection for genotyping (researcher) } \\
\text { - Reading motivation (researcher) } \\
\text { - Vocabulary (researcher) }\end{array}$ \\
\hline Intervention & $\begin{array}{l}\text { Week } 2-9 \text {, } \\
8 \text { hours in total }\end{array}$ & $\begin{array}{l}\text { - } 3 \text { or } 6 \text { students per classroom } \\
\text { - Randomly divided over three conditions, I or } 2 \text { stu- } \\
\text { dents per classroom per condition } \\
\text { - Condition I: Reading hardcopy (print) books } \\
\text { - Condition 2: Reading digital books without guidance } \\
\text { - Condition 3: Reading digital books with PA guidance }\end{array}$ \\
\hline Posttest & Week 10 & $\begin{array}{l}\text { - Reading motivation (researcher) } \\
\text { - Vocabulary (researcher) }\end{array}$ \\
\hline
\end{tabular}

participated. In each classroom, one or two students were randomly assigned to each condition. Buccal swabs were used to collect saliva for genotyping. After the study, the saliva was analyzed to make a distinction between genetically susceptible and low-susceptible individuals. At the time of the random assignment, researchers were unaware of whether participants were genetically susceptible or not.

\section{Participants}

Twenty-eight fifth-grade classrooms in 21 regular primary education schools across the Netherlands participated in this study. On average, the researchers received informed consent for $30 \%$ of students approached. The number of students with informed consent per classroom varied from 4 to 17 . After the selection of three or six participants per classroom, and the exclusion of one participant who missed the posttest, 146 participants $\left(M_{\text {age }}=11.10\right.$ years, $S D=.53$, range: $10.17-12.92$ years) remained, 76 , or $52.1 \%$, of which were girls.

\section{Materials}

Books. Thirteen Dutch age-appropriate books were selected for inclusion in the digital reading conditions (see Table A1 for an overview of the books). The books differed in length (51-197 pages), difficulty, and genre including a mix for boys' interests (e.g., horror), girls' (e.g., horses), and unisex themes (e.g., history). Researchers avoided the selection of popular children's books, books high on bestseller lists, and books used to create television series or films, but 
they rather selected recently published books to prevent student familiarity with the books. Prior to the intervention, students recognized an average of 1.47 out of 13 of the target books $(S D=1.79)$. Books were selected from three difficulty levels so students would not read books inappropriate for their reading level. Each book selection contained seven books. Classification was partly based on the book's length (above average $M_{\text {pages }}=141$, average $M_{\text {pages }}=100$, and below average $\left.M_{\text {pages }}=89\right)$ and partly on the first author's estimate of the difficulty of the books based on the complexity of the grammar and vocabulary. The two criteria were not always concordant. For instance, based on length, a book might fall in the average category, but based on the content — only short, single-line sentences and a simple story structure - it was placed in the easy category. The first author's estimate was used when the criteria were not concordant. Students were assigned to a difficulty level based on their score on a standardized reading comprehension test (Weekers, Groenen, Kleintjes, \& Feenstra, 2011). Students scoring in the lowest $25 \%$ were assigned to the easy selection $(n=20)$, students scoring average were assigned to the average selection $(n=48)$, and students scoring in the upper $25 \%$ were assigned to the difficult books selection $(n=29)$.

Infrastructure for delivery of digital books. For the delivery of the digital versions of the books, the researchers used a web-based application called IMapBook (Smith, 2013; www.imapbook.org) that has been used in prior studies on reading and vocabulary learning (Smith et al., 2013). IMapBook provides convenient authoring of game-like interaction in web-based books, along with user logins, customized bookshelves, an interface in a variety of languages (English, Dutch, Spanish, Chinese, etc.), and tracking of participants' reading, interaction, and game-play behavior in the web-based books. In the current study, IMapBook enabled the researchers (nonprogrammers) to create interactive digital versions of the 13 Dutch fiction books appropriate for 9- to 11-year-olds. The text and illustrations in the digital books were exactly the same as in the print versions. The number of words on pages of books was adjusted to avoid the need for scrolling. Students in the digital reading conditions had access to their own personal bookshelf by logging into the IMapBook website. They saw only the selection of books at their appropriate reading level. The IMapBook database registered how much time each child spent reading per session, in total, and on which pages, as well as a record of their interactions with the PA, which enabled a check on the fidelity of the intervention.

PA guidance. The guidance in the Digital-PA condition was provided by an animated mouse character (see Figure 1 for a screen shot of the PA) with accompanying prerecorded sound fragments. The oral message also appeared as text. The PA (which most students liked) was designed to encourage a student perception of intensive, closely monitored, and individualized guidance. Guidance was book-specific and always provided at the end of a chapter, 11 


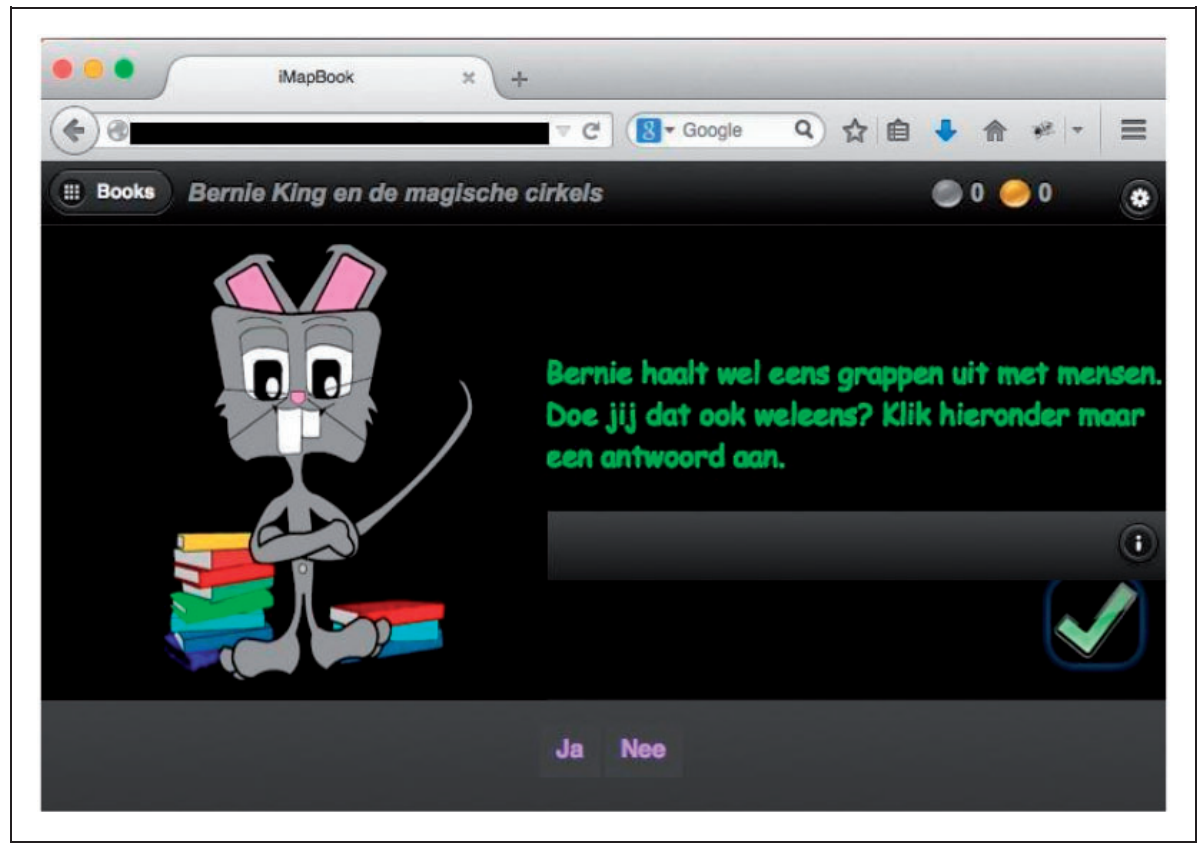

Figure I. A screen shot showing the animated Pedagogical Agent used in the study. The guidance was presented in text as well as oral form.

In this example, the mouse asks the child whether he or she sometimes plays a joke on friends just as Bernie, the main character in the story. The child responds by checking ja (yes) or nee (no).

to 15 times in each book. Each cycle had a duration of 25 to 60 seconds and included the following components:

1. The mouse complimented the reader, for example: "You finished another chapter, great job!"

2. The mouse summarized the key information in the chapter(s) the reader has just finished to support reading comprehension: "Faiza has had an argument with her best friend."

3. The mouse asked a question about personal experiences, similar to the preceding story excerpt, that students might have had: "Have you ever had a fight with your best friend?" or "Do you have a dog?"

4. The reader responded to the question by clicking on one of the multiplechoice options (e.g., yes or no).

5. There were no right or wrong answers, the mouse responded to the reader's answer in an encouraging way (e.g., "That's what I thought too"). The mouse than encouraged the reader to continue reading with a statement referring to the content of the book (e.g., "Alright, let's read further to find out what Faiza will do to solve the problem"). 


\section{Procedure}

In each classroom, all parents were asked for informed consent for both participating in the reading experiment and genotyping based on saliva. After the pretest was administered, the participants read books for 8 hours, approximately 1 hour per week, for 8 weeks. In the digital reading conditions, the progress was registered in a database that was only accessible by the researcher. This information enabled the researcher to check whether students spent sufficient time reading the books. Access to the digital reading program was blocked after students reached 8 hours of reading. Once a week, teachers received an overview of time that each student spent on reading. If students had not read at least 1 hour per week, the researcher contacted the teachers to ask about reasons and encourage more reading. Teachers were also asked to urge the students in the print book control condition to read. Which books this group read and whether this group indeed spent the same time reading was not monitored by the researchers nor was the reading setting of any of the students in this experiment (e.g., inside or outside of the classroom).

Pre- and posttests were administered by the first author or trained research assistants. Undergraduate students, who had been instructed and were blinded from the condition in which students had practiced reading coded the results. A random selection of $25 \%$ of the data were also coded by the first author. Intraclass correlation coefficients (ICC) for all measurement instruments was satisfactory; $r$ equaled .98 (vocabulary measure) or higher.

\section{Measurement Instruments}

Reading motivation. Participants were asked to rate 16 words and 24 pictures on a 6-point Likert-scale ranging from 0 for very negative to 5 for very positive. The words were eight reading-related and eight neutral words matched on word length (see Table A2) and familiar (e.g., book and building) to fifth graders. The pictures were 12 depictions of everyday activities that were not expected to elicit strong emotions matched with 12 reading-related pictures (see Figure 2 for an example). The criteria for matching reading-related and neutral images were the size and color of objects in each image. Pictures were also matched on the presence or absence of human faces and animals.

Alpha reliabilities for reading items and matched neutral items were .94 (preand posttest) and .85 (pre- and posttest), respectively. The researchers calculated difference scores by subtracting the average neutral score from the average reading score, as an indicator of reading motivation. Students with negative scores rated neutral items higher than reading items, indicating that they had negative feelings about reading. Students with positive scores rated reading items higher than neutral items, indicating positive feelings about reading. The main advantage of this measure is that it does not explicitly ask students about their 


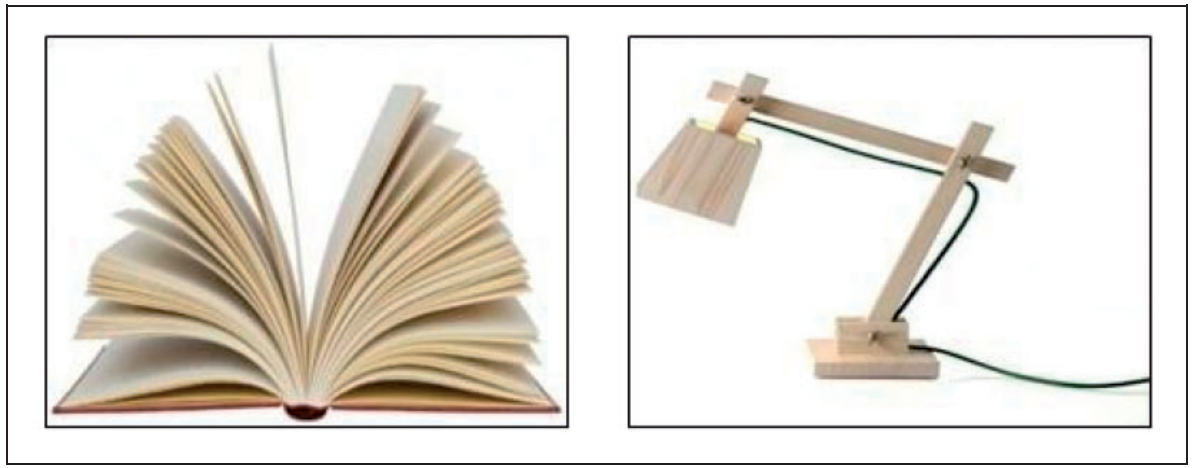

Figure 2. A reading picture (left) and a matched neutral picture (right) used in the picture evaluation task.

motivation. Instead, it is a more implicit measure that reduces the bias of socially desirable answers. The average of the neutral items provided an indication of how participants rate pictures and words in general. Comparing this average to the average rating of the reading-related pictures provided an indication of the participants' motivation for reading. Meta-analytic findings have shown that, compared with typical students, rarely reading students score significantly lower on this task (Nielen, Mol, Sikkema-de Jong, \& Bus, 2016).

Vocabulary. Vocabulary learning was measured via a researcher-designed bookbased word recognition checklist, using the yes/no test (Anderson \& Freebody, 1983). This is a method to test receptive vocabulary knowledge using a list of difficult words from the target books to which the researchers added pseudowords. Participants were explicitly told that the list contained pseudo-words and were asked to indicate for each word whether it is an existing word or not. The percentage of pseudo-words checked by students was subtracted from the percentage of real words checked, to correct for guessing. A high percentage score reflects a large vocabulary (many real words recognized and none or only a few pseudo-words). This yes/no test has previously been used in studies targeting first and second language learning (e.g., Mochida \& Harrington, 2006) and is strongly related to reading comprehension (Anderson, Wilson, \& Fielding, 1988). The alpha reliability of the word recognition checklist was satisfactory (pretest $\alpha=.93$; posttest $\alpha=.95$ ).

Five low-frequency words (e.g., miraculous, agitated) were selected from each of the 13 experimental books according to the following criteria: (a) a frequency below one occurrence per million words according to SUBTLEX-NL database (Keuleers, Brysbaert, \& New, 2010), (b) the words appeared in the books but not with more than a frequency of once per chapter, and (c) the words did not occur more than twice in any one book. The researchers added 33 pseudo-words to this 
list as foils (e.g., howrelsers), created by inserting low-frequency words from the target books (e.g., roddelpers) not included in the checklist, into Wuggy, a multilingual pseudo-word generator (Keuleers \& Brysbaert, 2010).

Reading ability. Students' reading ability was assessed using a standardized reading comprehension test (Cito Reading Comprehension; Weekers et al., 2011) that was administered in all participating schools prior to this experiment. Reading ability scores were thus available only as a pretest measure. Students scored in one of the following five categories based on Dutch national norms: $0=$ lowest $10 \%, 1=15 \%$ well below average, $2=25 \%$ right below average, $3=25 \%$ right above average, and $4=$ highest $25 \%$.

Genotyping. Buccal swabs were collected from individuals to assess the DRD4 marker for differential susceptibility, a method validated by Boor et al. (2002). The swabs were incubated in a lysis buffer $(100 \mathrm{mM} \mathrm{NaCl}, 10 \mathrm{mM}$ EDTA, $10 \mathrm{mM}$ Tris $\mathrm{pH} 8,0.1 \mathrm{mg} / \mathrm{ml}$ proteinase $\mathrm{K}$, and $0.5 \% \mathrm{w} / \mathrm{v}$ SDS) until further processing. Genomic DNA was isolated using the Chemagic buccal swab kit on a Chemagen Module I workstation (Chemagen Biopolymer-Technologie AG, Baesweiler, Germany). The region of interest of the DRD4 gene was amplified by PCR using the following primers: a FAM-labeled primer 5'GCGACTACGTGGTCTACTCG-3', and a reverse primer 5'-AGGA CCCTCATGGCCTTG-3'. Typical PCR reactions contained between 10 and $100 \mathrm{ng}$ genomic DNA template, $10 \mathrm{pmol}$ of forward and reverse primer. PCR was carried out in the presence of a 7.5\% DMSO, $5 \times$ buffer supplied with the enzyme and with $1.25 \mathrm{U}$ of LongAmp Taq DNA Polymerase (NEB) in a total volume of 301 using the following cycling conditions: initial denaturation step of 10 minutes at $95^{\circ} \mathrm{C}$, followed by 27 cycles of 30 seconds $95^{\circ} \mathrm{C}, 30$ seconds $60^{\circ} \mathrm{C}$, 60 seconds $65^{\circ} \mathrm{C}$, and a final extension step of 10 minutes $65^{\circ} \mathrm{C}$. One 1 of PCR product was mixed with 0.31 LIZ-500 size standard (Applied Biosystems) and 11.71 formamide (Applied Biosystems) and run on an AB 3730 genetic analyzer set up for fragment analyses with $50 \mathrm{~cm}$ capillaries. Results were analyzed using GeneMarker software (Softgenetics).

Based on the genotyping results, children were assigned to one of two groups: (a) a susceptible group with at least one DRD4 seven-repeat allele $(36 \%, n=52)$ or (b) a low-susceptible group with no DRD4 seven-repeat alleles $(64 \%, n=94)$. The two genotypes were in Hardy-Weinberg equilibrium, $\chi^{2}(1,146)=.06$, $p=.81$, meaning that the genotype distribution in our sample is comparable to the genotype distribution in the population.

\section{Data Analysis}

To assess main effects of intervention conditions and susceptibility and the interaction of intervention conditions and susceptibility, the posttest scores on 
reading motivation and vocabulary were regressed on the pretest score on reading motivation and vocabulary, genetic susceptibility (DRD4 seven-repeat allele absent vs. present), and two contrasts. The first contrast, print versus digital, compared the hardcopy book reading condition with the two digital reading conditions (paper coded as -2 , Digital-NoPA and Digital-PA coded as +1 ). The second contrast compared the Digital-NoPA with the Digital-PA group (Digital-NoPA coded as -1 , paper book group coded as 0 , and the DigitalPA group coded as +1$)$.

\section{Results}

\section{Intervention Fidelity}

Researchers asked students how they considered the difficulty level of their sets of books in the digital conditions. On a 4-point scale, only a minority of students reported that the books were much too difficult $(2 \%)$ or much too easy' $(17 \%)$. The remainder of the students reported the books were slightly too easy $(74 \%)$ or slightly too difficult $(7 \%)$, which validated the procedure used to assign students to the difficult, average, or easy book collection, based on their reading ability scores.

The reading time, as registered in the online database, provided the opportunity to monitor whether students indeed read at least an hour per week. In seven of the classrooms, students read at least 1 hour per week without any encouragement from the researcher. In the other 21 classrooms, it was less common to read on a regular basis and researchers had to encourage teachers bi-weekly or weekly. Despite the regular encouragement, there were 40 children in the digital reading conditions $(41 \%)$ who read less than 8 hours over 8 weeks ( $M=7$ hours and 16 minutes, $S D=52$ minutes). However, there were no differences between the average amount of time spent reading in the DigitalPA condition ( $M=7$ hours and 47 minutes, $S D=45$ minutes) and the DigitalNoPA condition ( $M=7$ hours and 48 minutes, $S D=40$ minutes), $t(95)=.07$, $p=.96$. Most students read approximately three books during the intervention. The PA in the Digital-PA condition encouraged the students approximately 45 times.

\section{Representativeness of the Sample}

To gain an indication of the representativeness of the sample, the distribution of scores on the standardized reading comprehension test were compared with the national distribution in the Netherlands. This is especially important given the relatively low participation rate that might result in a biased sample. The results in Table 2 indicate that this was not the case. The distribution of scores in this study's sample was reasonably comparable to the national distribution of scores. 
Table 2. Comparison of the Participants' Scores on the Standardized Reading Comprehension Test With the National Distribution.

\begin{tabular}{lccccr}
\hline Score & 0 & 1 & 2 & 3 & 4 \\
\hline National distribution (\%) & 10 & 15 & 25 & 25 & 25 \\
Participant distribution (\%) & 7 & 14 & 30 & 23 & 27 \\
\hline
\end{tabular}

Table 3. Correlations Between the Measurement Instruments.

\begin{tabular}{lllll}
\hline & 1 & 2 & 3 & 4 \\
\hline I. Reading ability & - & & & \\
Pretest & & & & \\
$\quad$ 2. Vocabulary & .50 & - & & \\
$\quad$ 3. Reading motivation & .29 & .30 & - & - \\
Posttest & & & & .37 \\
$\quad$ 4. Vocabulary & .48 & .79 & .31 & - \\
5. Reading motivation & .38 & .35 & .77 & \\
\hline
\end{tabular}

Note. All correlations are significant at the $p<.01$ level.

\section{Missing Data}

For the word/picture evaluation task, $0.25 \%$ and $0.08 \%$ of the items were missing for the pre- and posttest, respectively, and $0.35 \%$ and $0.35 \%$ of the items for the vocabulary measure. Missing scores were imputed based on the nonmissing scale items.

\section{Validity of Measurement Instruments}

To test the validity of our measurement instruments, the researchers have examined the correlation between reading ability, reading motivation, and vocabulary. Table 3 shows correlations for both pretest (reading ability, reading motivation, and vocabulary) and posttest (reading motivation and vocabulary). Correlations between the three measures were moderate and correlations between the pre- and posttests of the motivation and vocabulary measures equaled .77 and .79 , respectively. This indicates a rather high test-retest stability.

\section{Similarity of Participants in the Three Conditions}

Susceptible children (children with the DRD4 seven-repeat allele) were equally distributed over the conditions, as shown in Table 4. Both susceptible and 
Table 4. Means (Standard Deviations) for the Pre- and Posttest Reading Motivation and Vocabulary Measure.

\begin{tabular}{|c|c|c|c|c|c|c|}
\hline & & \multirow{2}{*}{$n$} & \multicolumn{2}{|c|}{ Reading motivation } & \multicolumn{2}{|c|}{ Vocabulary } \\
\hline & & & Pre & Post & Pre & Post \\
\hline \multirow[t]{2}{*}{ Paper } & Susceptible & 17 & $.36(0.85)$ & $.67(0.78)$ & 34.49 (15.85) & $39.15(18.81)$ \\
\hline & Low-susceptible & 32 & $.43(0.83)$ & $.45(1.01)$ & $29.97(16.82)$ & 32.49 (15.99) \\
\hline \multirow[t]{2}{*}{ Digital-NoPA } & Susceptible & 17 & $.34(1.00)$ & $.46(1.30)$ & 34.46 (15.73) & 34.65 (15.97) \\
\hline & Low-susceptible & 31 & $.63(1.20)$ & $.76(1.09)$ & $36.60(16.87)$ & $39.86(\mid 7.31)$ \\
\hline \multirow[t]{2}{*}{ Digital-PA } & Susceptible & 18 & $.64(1.03)$ & $.82(1.03)$ & $39.82(17.33)$ & $45.10(17.50)$ \\
\hline & Low-susceptible & 31 & $.57(\mathrm{I} .4 \mathrm{I})$ & $.52(1.04)$ & 33.89 (13.80) & 34.67 (15.35) \\
\hline
\end{tabular}

Note. $\mathrm{PA}=$ Pedagogical Agent.

low-susceptible students were slightly more positive towards the reading pictures than the neutral pictures on both the pre- and posttest. For the vocabulary test, they recognized about $35 \%$ (23 out of 65 ) of the difficult words on the pretest and $38 \%$ (25 out of 65 ) of the difficult words on the posttest. ANOVAs with condition (paper book reading, Digital-NoPA, Digital-PA) and susceptibility (DRD4 seven-repeat allele absent vs. present) as between-subject factors and pretest scores on motivation, reading ability, and vocabulary as dependent variables did not reveal significant effects which indicates that the randomization was successful $(F<1.40, p s>.25)$.

\section{Effects of the Intervention on Motivation and Vocabulary}

Reading motivation and vocabulary learning were regressed on pretest scores, contrasts (print vs. digital and Digital-NoPA vs. Digital-PA), susceptibility (DRD4 seven-repeat allele absent vs. present), and the interactions between the contrasts and susceptibility. The regression models explained $61 \%, F(6$, $139)=36.06, p<.001$, and $63 \%, F(6,139)=39.77, p<.001$, of reading motivation and vocabulary posttest scores, respectively; see Table 5.

Neither for reading motivation nor vocabulary learning did the print versus digital contrast cause a significant main effect, indicating that reading in a digital format was as effective as the print (hardcopy) format. Also for the full sample, no effects of the contrast between digital reading with and without PA were found, which suggests that the presence of a PA did not influence the attitude of the full sample of students towards reading, nor did it enhance their vocabulary learning.

Based on nonsignificant interactions between the print versus digital reading contrast and susceptibility, print versus digital reading did not differentially influence motivation or vocabulary learning of the susceptible individuals. 
Table 5. Regression Analyses Examining the Effects of the Intervention on Reading Motivation and Vocabulary Learning Accounting for the Pretest and Susceptibility.

\begin{tabular}{|c|c|c|c|c|c|}
\hline & B & $S D$ & $\beta$ & $t$ & $p$ \\
\hline \multicolumn{6}{|l|}{ Reading motivation posttest } \\
\hline Reading motivation pretest & .74 & .05 & .77 & 14.48 & $<.001$ \\
\hline Print vs. digital & .02 & .05 & .03 & .46 & .65 \\
\hline Digital-NoPA vs. Digital-PA & -.10 & .09 & -.08 & -1.15 & .25 \\
\hline Susceptibility & .14 & .12 & .07 & 1.25 & .22 \\
\hline Print vs. digital $\times$ Susceptibility & -.06 & .08 & -.05 & -.78 & .44 \\
\hline Digital-NoPA vs. Digital-PA $\times$ Susceptibility & .16 & .14 & .08 & 1.16 & .25 \\
\hline \multicolumn{6}{|l|}{ Vocabulary posttest } \\
\hline Vocabulary pretest & .81 & .06 & .77 & $14.7 \mid$ & $<.001$ \\
\hline Print vs. digital & .17 & .77 & .01 & .22 & .83 \\
\hline Digital-NoPA vs. Digital-PA & -1.50 & 1.33 & -.07 & -1.13 & .26 \\
\hline Susceptibility & 1.72 & 1.82 & .05 & .95 & .35 \\
\hline Print vs. digital $\times$ Susceptibility & -.64 & 1.28 & -.03 & -.50 & .62 \\
\hline Digital-NoPA vs. Digital-PA $\times$ Susceptibility & 4.55 & 2.22 & .13 & 2.05 & .04 \\
\hline
\end{tabular}

Note. PA = Pedagogical Agent.

In other words, it did not make a difference to the susceptible individuals whether they read print (hardcopy) or digital texts. However, based on a significant interaction between the Digital-NoPA and Digital-PA contrast and susceptibility (see Figure 3), the presence of the PA did significantly improve vocabulary learning in the susceptible group $(p$ one-sided $=.04)$ with a large effect size $(d=.69)$.

\section{Characteristics of the Interaction Between Susceptibility and Feedback}

Widaman et al. (2012) describe a procedure to test if an interaction is disordinal, as may be expected when only some of the students benefit from the intervention. The susceptible group is expected to be responsive to the intervention while the low-susceptible group is not. Following Widaman's procedure, it was found that the crossover point (as displayed in Figure 3) was located about halfway between the dummy-coded conditions $(-0.38 ; 95 \% \mathrm{CI}:-1.25,-.49)$, which is typical for a disordinal interaction (Widaman et al., 2012). Because the lower bound of the confidence interval fell outside the range of the dummy-coded conditions, we cannot conclude that the interaction is probably disordinal in new samples. In two regression analyses, the posttest vocabulary scores for the susceptible and low-susceptible children were predicted separately controlling 


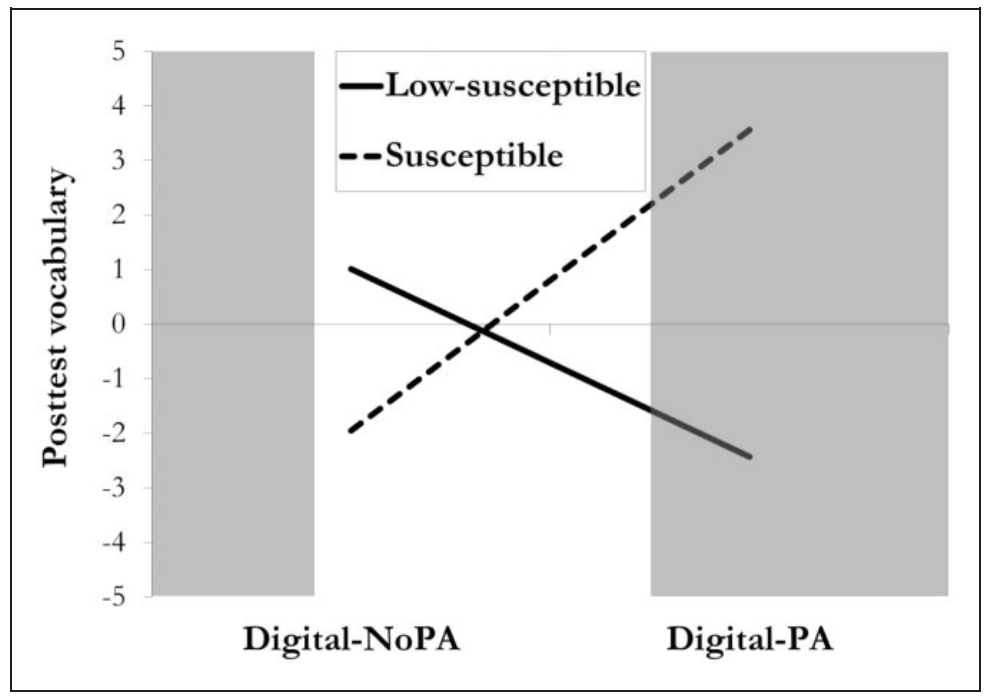

Figure 3. The interaction between the Digital-NoPA and Digital-PA contrast and susceptibility. The gray areas show the boundaries of a $95 \% \mathrm{Cl}$ around the crossover point (Widaman et al., 20I2).

$\mathrm{PA}=$ Pedagogical Agent.

for the pretest vocabulary scores. Feedback in the digital reading materials was a nonsignificant predictor for low-susceptible children $(\beta=-.08, p=.26)$, explaining $0.6 \%$ of the variance in the posttest vocabulary scores. However, for susceptible children, feedback was a significant predictor $(\beta=.13$, one-sided $p=.05)$ explaining $1.7 \%$ of the variance in the posttest vocabulary scores. This finding provides further evidence for the hypothesis that for the low-susceptible group the presence or absence of feedback did not influence learning whereas susceptible children did profit from the feedback during reading.

\section{Discussion}

This study revealed no support for the hypothesis that the medium (print vs. digital) influences student reading motivation and reading comprehension (e.g., Daniel \& Woody, 2013; Mangen et al., 2013; Miranda et al., 2011; Tveit \& Mangen, 2014). The reading motivation of the fifth graders in this study did not change due to reading in digital format, nor did they learn more new vocabulary than their peers reading hardcopy print books.

However, we did find support for the notion that susceptible students benefit from the presence of a pedagogical agent (e.g., Kegel et al., 2011; Plak et al., 2015). Susceptible students who read digital books with guidance from a PA 
learned more new vocabulary than susceptible children reading digital books without guidance. For low-susceptible students, in contrast, the presence of the PA did not result in more vocabulary learning.

\section{Potential of Digital Reading}

Studies comparing digital to print reading often focus on reading comprehension of short texts in an educational setting (e.g., Daniel \& Woody, 2013; Mangen et al., 2013; Taylor, 2011). We took a different approach and gave students the opportunity to choose their own reading materials and read digital texts over a longer period of time. Furthermore, in contrast to previous studies that measured whether students preferred print or digital reading (e.g., Tveit \& Mangen, 2014), it was explored how digital reading influences the motivation towards reading in general. This may explain why we did not find differences in reading motivation: If students have to read, they may prefer to read digital texts. Reading digital texts, however, does not necessarily change their motivation, even if they have the opportunity to read entire books.

As digital reading is becoming more and more widespread (about $40 \%$ of Dutch adolescents and young adults occasionally read digital books; Witte \& van Nood, 2014), it becomes vital to focus on how digital reading materials can be designed so that the materials support students during reading. In this study, it was tested whether a feature that is only feasible in digital books, a PA providing guidance during reading, supports reading motivation and vocabulary learning. The PA did not have a main effect on reading motivation and vocabulary learning when the researchers looked at the entire sample.

However, in accordance with the differential susceptibility notion-some individuals are more susceptible to quality of instruction than others - it was found that susceptible students benefited from the intervention, whereas low-susceptible students did not. Susceptible students - carriers of the DRD4 seven-repeat allele - identified through genotyping, were more sensitive to the encouragements from the PA than their low-susceptible peers. For the susceptible students, guidance during reading had a moderately large effect on vocabulary learning $(d=.69)$, whereas it had a nonsignificant effect $(d=-.25)$ on word learning for low- susceptible students. This study thus contributes to the accumulating evidence suggesting that children with the DRD4 seven-repeat allele are more responsive to educational interventions (Kegel et al., 2011; Plak et al., 2015); current findings extend previous findings in the field of emergent literacy to an older age-group in need of reading practice.

The children without the DRD4 seven-repeat allele, and thus less susceptible to guidance, tended to score lower on the vocabulary learning posttest in the PA condition than in the non-PA condition, but the difference did not reach significance (see Figure 3). A question that is open for further studies is whether these 
nonsusceptible children progress well without guidance or perhaps need a different type of guidance. For instance, a stronger and more challenging computer game-style of guidance, as opposed to the gentle and nurturing guidance that was effective for the susceptible students. On the other hand, challenging additions might distract the student from the story line because it implies another task, thus affecting story comprehension negatively (cf. Bus, Takacs, \& Kegel, 2015). In support of the latter, it is worth mentioning that some students informally commented during the study that they would rather read without the PA. For interactive books to be effective for the full population, there might need to be adaptive individualization or differentiation. Based on the current research, it is unclear whether interaction and guidance can be formatted in ways beneficial to all students.

Over the course of primary and secondary school, many students stop reading (OECD , 2010) and thus fail to consolidate their reading skills. The reason for the discontinuation of reading may be that many students are expected to read independently too early in their development (Kirschner et al., 2006). Especially for readers, for whom it is challenging to stay focused while reading, reading may become an increasingly frustrating activity and eventually students may start to avoid reading. To the best of our knowledge, this is the first study that provides experimental support for the notion that guidance during digital reading can support students at the end of primary school while reading selfselected fiction books. The significant results (for the susceptible children) strongly suggest the need for guidance customized towards their attention problems.

The researchers did not find any evidence for changes in students' reading motivation after 8 hours of digital reading with guidance. However, the reciprocal causal relationship between reading comprehension and reading motivation suggests that an appropriately differentiated intervention supporting reading comprehension may eventually support reading motivation as well (Becker, McElvany, \& Kortenbruck, 2010; Morgan \& Fuchs, 2007; Mol \& Bus, 2011). Therefore, guidance during reading may enhance the motivation to read as well in the long run.

\section{Limitations}

The multidisciplinary nature of this research and the strong orientation towards the natural classroom setting inevitably resulted in some flaws in the design. In this first study of a PA supporting students during the reading of self-selected books in school, the researchers incorporated several elements of evidence-based practices with human tutors into the PA design. The PA praised the students, helped them to understand the story, related story elements to students' personal experiences, and encouraged students to continue reading. A disadvantage of 
this extensive guidance is that it remains unclear whether a combination of these elements or a single element (e.g., praise) helps susceptible children to learn more from reading. Because it is unclear which elements of the PA (or the design of the PA itself; Baylor, 2011) cause the effects on reading comprehension, it is difficult to deduce the type of support susceptible students miss when reading without a PA. Based on previous research, it is however, plausible that the susceptible students are easily distracted and become more stressed when a task is difficult (Kegel et al., 2011). Future studies comparing different types of feedback to assess what kind of support is most beneficial for susceptible students to focus on reading and minimize feelings of stress would be very interesting.

The possibility for students to choose from different books is a strong point for the ecological validity of the study. However, this free choice also prevented the creation of a book-based reading comprehension measure within the limitations of the test battery capacity. Future studies should address effects on a larger variety of book-based measures and attempt to relate any improvements to more general reading and reading motivation outcome measures (e.g., assessing the effect of a long-term intervention on both the book-based and general vocabulary learning). However, such effects can only be expected from longer and more intensive interventions.

The behavioral mechanisms underlying the effect of feedback on susceptible students' vocabulary learning are not explicitly tested in the present study. Gaining more insight into these mechanisms may help unravel the underlying genetic pathway that makes carriers of the DRD4 seven-repeat allele more susceptible to educational interventions providing individualized feedback. Ideally, more easily observable characteristics, such as behavior and attitudes inferred from interactions with PAs, may be found that indicate whether individuals are susceptible or not (Plak et al., 2015). Despite these uncertainties, an increasing number of studies indicate the usefulness of the DRD4 polymorphism to detect differential susceptibility, both in psychopathology and education (van IJzendoorn \& Bakermans-Kranenburg, 2015).

\section{Conclusions}

This study provides preliminary evidence for the potential benefits of digital reading with PAs. There appears to be much promise in this area of research, especially in the domain of independent reading of self-selected books, both in school and in leisure time. This type of reading practice is important in the development of literacy skills and thereby for educational attainment and professional success (Gottfried et al., 2015; Mol \& Bus, 2011) but is generally considered to be the student's own responsibility. Some students manage to keep practicing and become skilled and enthusiastic readers. A large number of 
students, however, lose interest in reading over the course of primary and secondary education (e.g., OECD, 2010). This study shows the potential of digital reading to continuously support reading development, particularly for readers with a predisposition towards attention problems. More research is needed to determine the most effective design and to optimize the digital guidance.

This study also provides some support for the notion that reading comprehension and motivation of fifth graders does not seem to be hampered by reading in a digital instead of a print format. Furthermore, accumulating evidence (Kegel et al., 2011; Plak et al., 2015) including the results presented in this article suggest that for a minority of children (carriers of the DRD4 seven-repeat allele) learning outcomes are strongly dependent on the presence or absence of guidance. In the present study, it was shown that guidance provided by a PA helps susceptible students to learn more from reading. As students' learning environment becomes increasingly digital, the opportunities to provide frequent, adaptive, and individual feedback will grow (Vasilyeva, 2007). More research into the characteristics that make digital reading programs effective, and for whom, should inform the design of evidence-based programs that help students reach their full potential.

\section{Appendix}

Table AI. Dutch Children's Books Used in the Experiment.

\begin{tabular}{lll}
\hline & \multicolumn{1}{c}{ Author } & \multicolumn{1}{c}{ Title } \\
\hline I. & Nicolle Christiaanse & De Bleshof: Alles voor mijn paard \\
2. & Cornelia Funke & Ridder zonder hart \\
3. & Hans Hagen & Het hanengevecht \\
4. & Annet Jacobs & Het geheim van de dansende beer \\
5. & Netty van Kaathoven & Faiza is mijn held \\
6. & Mirjam Oldenhave & Control \& Copy \\
7. & Mirjam Oldenhave & Rampenkamp \\
8. & Hans Petermeijer & Potvis op het strand! \\
9. & Ruben Prins & Het geheim van de vergiftigde hond \\
10. & Daan Remmerts de Vries & Bernie King en de magische cirkel \\
I1. & Lydia Rood & Marietje Appelgat \\
12. & Jacques Vriens & Stijd om de kathedraal \\
13. & Anna Woltz & De pizza spion \\
\hline
\end{tabular}


Table A2. Words in the Word/Picture Evaluation Task (Dutch Translation).

\begin{tabular}{lll}
\hline & Reading words & Matched neutral words \\
\hline I. & book (boek) & door (deur) \\
2. & cover (kaft) & flat (vlak) \\
3. & read (lezen) & kettle (ketel) \\
4. & title (titel) & next to (naast) \\
5. & comic strip (strip) & wagon (wagen) \\
6. & letter (letter) & building (gebouw) \\
7. & page (pagina) & finger (vinger) \\
8. & story (verhaal) & headlight (koplamp) \\
\hline
\end{tabular}

\section{Declaration of Conflicting Interests}

The authors declared no potential conflicts of interest with respect to the research, authorship, and/or publication of this article.

\section{Funding}

The authors disclosed receipt of the following financial support for the research, authorship, and/or publication of this article: For this research, A. G. Bus received a grant from "Art of Reading" (Kunst van Lezen), a project funded by the Dutch Ministry of Education, Culture and Science (OCW) and a grant from the "Dutch Reading Association" (Stichting Lezen).

\section{References}

Anderson, R. C., \& Freebody, P. (1983). Reading comprehension and the assessment and acquisition of word knowledge. In B. Hutson (Ed.), Advances in reading/language research (pp. 231-256). Greenwich, CT: JAI Press.

Anderson, R. C., Wilson, P. T., \& Fielding, L. G. (1988). Growth in reading and how children spend their time outside of school. Reading Research Quarterly, 23, 285-303. doi:10.1598/RRQ.23.3.2

Bakermans-Kranenburg, M. J., \& van IJzendoorn, M. H. (2011). Differential susceptibility to rearing environment depending on dopamine related genes: New evidence and a meta-analysis. Development and Psychopathology, 23, 39-52. doi:10.1017/S0954579 410000635

Baker, S., Gersten, R., \& Keating, T. (2000). When less may be more: A 2-year longitudinal evaluation of a volunteer tutoring program requiring minimal training. Reading Research Quarterly, 35(4), 494-519. doi:10.1598/RRQ.35.4.3

Baylor, A. L. (2011). The design of motivational agents and avatars. Educational Technology Research and Development, 59, 291-300. doi:10.1007/s11423011-9196-3 
Baylor, A. L., \& Kim, Y. (2005). Simulating instructional roles through pedagogical agents. International Journal of Artificial Intelligence in Education, 15, 95-115.

Becker, M., McElvany, N., \& Kortenbruck, M. (2010). Intrinsic and extrinsic reading motivation as predictors of reading literacy: A longitudinal study. Journal of Educational Psychology, 102(4), 773-785. doi:10.1037/a0020084

Belsky, J., Bakermans-Kranenburg, M. J., \& van IJzendoorn, M. H. (2007). For better and for worse: Differential susceptibility to environmental influences. Current Directions in Psychological Science, 16(6), 300-304.

Boor, K., Ronai, Z., Nemoda, Z., Gaszner, P., Sasvari-Szekely, M., Guttman, A., \& Kalasz, H. (2002). Noninvasive genotyping of dopamine receptor D4 (DRD4) using nanograms of DNA from substance-dependent patients. Current Medicinal Chemistry, 9(8), 793-797. doi:https://doi.org/10.2174/0929867024606821

Boorstin, D. J. (1984). Books in our future. Washington, DC: U.S. Government Printing Office.

Bus, A. G., Takacs, Z. K., \& Kegel, C. A. T. (2015). Affordances and limitations of electronic storybooks for young children's emergent literacy. Developmental Review, 35, 79-97. doi:http://dx.doi.org/10.1016/j.dr.2014.12.004

Chall, J. S. (1983). Stages of reading development. New York, NY: McGraw-Hill.

Cunningham, A. (2005). Vocabulary growth through independent reading and reading aloud to children. In M. Kamil \& E. Hiebert (Eds.), Teaching and learning new vocabulary: Bringing research to practice (pp. 45-68). Mahwah, NJ: Erlbaum.

Daniel, D. B., \& Woody, W. D. (2013). E-textbooks at what cost? Performance and use of electronic v. print texts. Computers \& Education, 62, 18-23. doi:10.1016/ j.compedu.2012.10.016

EU High Level Group of Experts on Literacy. (2012). EU High Level Group of Experts on Literacy: Final report, September 2012. Luxembourg: Publications Office of the European Union.

Gottfried, A. W., Schlackman, J., Gottfried, A. E., \& Boutin-Martinez, A. S. (2015). Parental provision of early literacy environment as related to reading and educational outcomes across the academic lifespan. Parenting, 15(1), 24-38. doi:10.1080/ 15295192.2015 .992736

Heidig, S., \& Clarebout, G. (2011). Do pedagogical agents make a difference to student motivation and learning? Educational Research Review, 6(1), 27-54. doi:10.1016/ j.edurev.2010.07.004

Johnson, W. L., Rickel, J. W., \& Lester, J. C. (2000). Animated pedagogical agents: Faceto-face interaction in interactive learning environments. International Journal of Artificial Intelligence in Education, 11, 47-78.

Kegel, C. A. T., Bus, A. G., \& van IJzendoorn, M. H. (2011). Differential susceptibility in early literacy instruction through computer games: The role of the dopamine D4 receptor gene (DRD4). Mind, Brain and Education, 5, 71-78. doi:10.1111/j.1751228X.2011.01112.x

Keuleers, E., \& Brysbaert, M. (2010). Wuggy: A multilingual pseudoword generator. Behavior Research Methods, 42, 627-633. doi:10.3758/BRM.42.3.627

Keuleers, E., Brysbaert, M., \& New, B. (2010). SUBTLEX-NL: A new measure for Dutch word frequency based on film subtitles. Behavior Research Methods, 42, 643-650. doi:10.3758/brm.42.3.643 
Kim, Y., \& Baylor, A. L. (2016). Research-based design of pedagogical agent roles: A review, progress, and recommendations. International Journal of Artificial Intelligence in Education, 26, 160-169. doi:10.1007/s40593-015-0055-y

Kirschner, P. A., Sweller, J., \& Clark, R. E. (2006). Why minimal guidance during instruction does not work: An analysis of the failure of constructivist, discovery, problem-based, experiential, and inquiry-based teaching. Educational Psychologist, 41(2), 75-86. doi:10.1207/s15326985ep4102_1

Lusk, M. M., \& Atkinson, R. K. (2007). Animated pedagogical agents: Does their degree of embodiment impact learning from static or animated worked examples? Applied Cognitive Psychology, 21(6), 747-764.

Mangen, A., Walgermo, B. R., \& Brønnick, K. (2013). Reading linear texts on paper versus computer screen: Effects on reading comprehension. International Journal of Educational Research, 58, 61-68. doi:http://dx.doi.org/10.1016/j.ijer.2012.12.002

Meyer, B. J. F., Wijekumar, K., Middlemiss, W., Higley, K., Lei, P.-W., Meier, C., \& Spielvogel, J. (2010). Web-based tutoring of the structure strategy with or without elaborated feedback or choice for fifth- and seventh-grade readers. Reading Research Quarterly, 45(1), 62-92. doi:10.1598/rrq.45.1.4

Mich, O., Pianta, E., \& Mana, N. (2013). Interactive stories and exercises with dynamic feedback for improving reading comprehension skills in deaf children. Computers \& Education, 65(0), 34-44. doi:http://dx.doi.org/10.1016/j.compedu.2013.01.016

Miranda, T., Williams-Rossi, D., Johnson, K. A., \& McKenzie, N. (2011). Reluctant readers in middle school: Successful engagement with text using the e-reader. International Journal of Applied Science and Technology, 1, 81-91.

Mochida, A., \& Harrington, M. (2006). The Yes/No test as a measure of receptive vocabulary knowledge. Language Testing, 23(1), 73-98.

Mol, S. E., \& Bus, A. G. (2011). To read or not to read: A meta-analysis of print exposure from infancy to early adulthood. Psychological Bulletin, 137(2), 267-296. doi:10.1037/ a0021890

Morgan, P. L., \& Fuchs, D. (2007). Is there a bidirectional relationship between children's reading skills and reading motivation? Exceptional Children, 73(2), 165-183.

Nielen, T. M. J., \& Bus, A. G. (2013). Ontwikkeling van de leesattitude op de basisschool en de rol van sekse, leesniveau, de leescultuur thuis en kenmerken van de schoolbibliotheek [Development of reading attitude in primary school and the role of gender, reading skill, home literacy environment and school library characteristics]. In D. Schram (Ed.), De aarzelende lezer over de streep [Winning reluctant readers over] (pp. 207-226). Delft, Nederland: Eburon.

Nielen, T. M. J., \& Bus, A. G. (2015). Enriched school libraries: A boost to academic achievement. AERA Open, 1(4), 1-11. doi:10.1177/2332858415619417

Nielen, T. M. J., Mol, S. E., Sikkema-de Jong, M. T., \& Bus, A. G. (2016). Attentional bias toward reading in reluctant readers. Contemporary Educational Psychology, 46, 263-271.

Notten, N. (2011). Parents and the media. Causes and consequences of parental media socialization (Doctoral Dissertation). Nijmegen, The Netherlands: Radboud University Nijmegen.

OECD. (2010). PISA 2009 Results: Learning to learn-Student engagement, strategies and practices (Volume III). Retrieved from http://www.oecd.org/pisa/pisaproducts/ 48852630.pdf. doi:10.1787/9789264083943-en 
Pappa, I., Mileva-Seitz, V. R., Bakermans-Kranenburg, M. J., Tiemeier, H., \& van IJzendoorn, M. H. (2015). The magnificent seven: A quantitative review of dopamine receptor $\mathrm{d} 4$ and its association with child behavior. Neuroscience and Biobehavioral Reviews, 57, 175-186.

Plak, R. D., Kegel, C. A. T., \& Bus, A. G. (2015). Genetic differential susceptibility in literacy-delayed children: A randomized controlled trial on emergent literacy in kindergarten. Development and Psychopathology, 27(Special Issue 01), 69-79. doi:M6310.1017/S0954579414001308

Pressley, M. (2006). Reading instruction that works: The case for balanced teaching. New York, NY: The Guilford Press.

Rimm-Kaufman, S. E., Kagan, J., \& Byers, H. (1998). The effectiveness of adult volunteer tutoring on reading among "at risk" first grade children. Reading Research and Instruction, 38(2), 143-152. doi:10.1080/19388079909558284

Schroeder, N. L., Adesope, O. O., \& Gilbert, R. B. (2013). How effective are pedagogical agents for learning? A meta-analytical review. Journal of Educational Computing Research, 49(1), 1-39. doi:10.2190/EC.49.1.a

Share, D. L. (2008). Orthographic learning, phonological recoding, and self-teaching. In R. V. Kail (Ed.), Advances in child development and behavior (Vol. 36, pp. 31-82). Waltham, MA: Academic Press.

Smith, G. G., Li, M., Drobisz, J., Park, H., Kim, D., \& Smith, S. D. (2013). Play games or study? Computer games in eBooks to learn English vocabulary. Computers \& Education, 69, 274-286. doi:10.1016/j.compedu.2013.07.015

Smith, G. G. (2013). IMapBooks [Online program]. Retrieved from http://www. IMapBooks.com/

Sung, Y.-T., Chang, K.-E., \& Huang, J.-S. (2008). Improving children's reading comprehension and use of strategies through computer-based strategy training. Computers in Human Behavior, 24(4), 1552-1571. doi:http://dx.doi.org/10.1016/j.chb.2007.05.009

Swanborn, M. S. L., \& de Glopper, K. (1999). Incidental word learning while reading: A meta-analysis. Review of Educational Research, 69(3), 261-285. doi:10.3102/ 00346543069003261

Sweller, J., Ayres, P., \& Kalyuga, S. (2011). Cognitive load theory. New York, NY: Springer.

Taylor, A. K. (2011). Students learn equally well from digital as from paperbound texts. Teaching of Psychology, 38(4), 278-281. doi:10.1177/0098628311421330

Taylor, M. (2013). Reading for pleasure in Britain: Trends, patterns, and associations. Oxford, England: University of Oxford.

Teale, W. H., Lyons, K., Gambrell, L., Zolt, N., Olien, R., \& Leu, D. J. (2013). An online learning community as support for at-risk students' literacy growth: Findings, implications, and challenges. In A. Shamir \& O. Korat (Eds.), Technology as a support for literacy achievements for children at risk (pp. 141-156). Dordrecht, Netherlands: Springer.

Tveit, A. K., \& Mangen, A. (2014). A joker in the class: Teenage readers' attitudes and preferences to reading on different devices. Library \& Information Science Research, 36(3-4), 179-184. doi:10.1016/j.lisr.2014.08.001

van IJzendoorn, M. H., \& Bakermans-Kranenburg, M. J. (2015). Genetic differential susceptibility on trial: Meta-analytic support from randomized controlled experiments. Development and Psychopathology, 27(Special Issue 01), 151-162. doi:10.1017/S0954579414001369 
Vasilyeva, E. (2007). Towards personalized feedback in educational computer games for children. Paper presented at the Sixth IASTED International Conference, Chamonix, France.

Weekers, A., Groenen, I., Kleintjes, F., \& Feenstra, H. (2011). Wetenschappelijke verantwoording papieren toetsen Begrijpend Lezen voor groep 7 en 8. [Scientific justification paper tests Reading Comprehension for 5th and 6th grade]. Arnhem, The Netherlands: Cito.

Widaman, K. F., Helm, J. L., Castro-Schilo, L., Pluess, M., Stallings, M. C., \& Belsky, J. (2012). Distinguishing ordinal and disordinal interactions. Psychological Methods, 17(4), 615-622. doi:10.1037/a0030003

Witte, E., \& van Nood, B. (2014). Rapportage boekenbranche meting 30: 2e thema meting van 2014, naar digitaal lezen [Report book branche measure 30: 2nd theme measure of 2014 , toward digital reading]. Retrieved from http://www.kvb.nl/feiten-en-cijfers/consumentenonderzoek/nov-2014.

\section{Author Biographies}

Thijs M. J. Nielen obtained his PhD from the Leiden University in 2016. His research in the field of education and child studies focuses on the effects of school libraries and the influence of digital reading materials on primary school students' reading ability and reading motivation.

Glenn G. Smith is an associate professor at the University of South Florida. His research interests include embedding computer games into eBooks to improve literacy, online learning, and spatial abilities.

Maria T. Sikkema-de Jong is an assistant professor at the Leiden University. Her research interests include young children's literacy and math development and the learning child in a digital world.

Jack Drobisz obtained his $\mathrm{PhD}$ in Instructional Technology from the University of South Florida in 2017. He holds BS and MS degrees in Computer Science from the University of Illinois and the University of South Florida. His interests include research on eBooks to improve literacy among struggling readers, situational interest, cognitive load, and Second Language Learners.

Bill van Horne holds a BS in Physics from the Georgia Institute of Technology, and an MEd in Educational Technology from the University of South Florida. He works as an educational programmer for various projects. Mr Van Horne currently is developing an adaptive learning system.

Adriana G. Bus is a professor in reading socialization at the Vrije Universiteit Amsterdam. Her research interests include storybook reading, e-reading, reading promotion, and differential susceptibility in reading acquisition. 